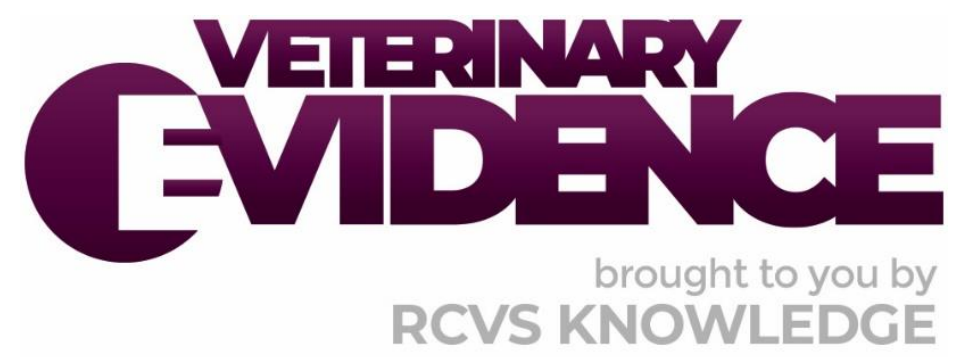

\title{
Can garlic prevent, repel or kill fleas that infest dogs?
}

\author{
A Knowledge Summary by
}

Louise Buckley PhD FHEA RVN ${ }^{1 *}$

\footnotetext{
${ }^{1}$ Edinburgh Surgery Online, Deanery of Clinical Sciences, College of Medicine \& Veterinary Medicine, University of Edinburgh, 196 Canongate, Edinburgh, EH8 8AQ

*Corresponding Author (louise.buckley@ed.ac.uk)
}

ISSN: 2396-9776

Published: 28 Aug 2020

in: The Veterinary Evidence journal Vol 5, Issue 3

DOI: 10.18849/VE.V5I3.311

Reviewed by: Virginia Fajt (DVM PhD DACVCP) and Roberta Perego (DVM PhD)

Next Review Date: 08 Dec 2021

\section{OPEN
ACCESS}




\section{KNOWLEDGE SUMMARY}

\section{PICO question}

In dogs, is oral or topical administration of garlic, compared to no treatment, efficacious at preventing or reducing parasitism by fleas?

\section{Clinical bottom line}

\section{Category of research question}

Treatment

The number and type of study designs reviewed

Zero

\section{Strength of evidence}

Critical appraisal of the selected papers meeting the inclusion criteria collectively provide zero evidence in terms of their experimental design and implementation

\section{Outcomes reported}

The outcomes reported were none

\section{Conclusion}

It is concluded that there is a lack of peer-reviewed scientific in vivo evidence to address the PICO

\section{How to apply this evidence in practice}

The application of evidence into practice should take into account multiple factors, not limited to: individual clinical expertise, patient's circumstances and owners' values, country, location or clinic where you work, the individual case in front of you, the availability of therapies and resources.

Knowledge Summaries are a resource to help reinforce or inform decision-making. They do not override the responsibility or judgement of the practitioner to do what is best for the animal in their care. 


\section{Clinical Scenario}

A veterinary nurse is reading through the ectoparasiticide advice being given in a Facebook group that encourages a 'natural' (non-conventional medicine) approach to preventative medicine in dogs. She notices that garlic is being recommended quite frequently by some pet owners as an alternative to a conventional ectoparasiticide for preventing or treating flea infestation on dogs and wonders what the evidence base is for this recommendation.

\section{The evidence}

No peer-reviewed scientific papers were identified that addressed the PICO. Widening the inclusion criteria to include garlic applied environmentally (the same search strategy was retained) to address extra dog environmental infestation, or case studies based on oral, topical or environmental application of garlic also yielded no results.

\section{Summary of the evidence}

There was no peer-reviewed evidence that met the inclusion criteria to summarise.

\section{Appraisal, application and reflection}

No in vivo studies that examine the efficacy of garlic at preventing, killing or repelling any stage of the flea life cycle in dogs were identified from the search strategy applied, and therefore no papers met the inclusion criteria for this Knowledge Summary. One in vitro study (Renapurkar \& Deshmukh, 1984) was identified which demonstrated that environmental application (on to filter paper) of garlic extract in a hexane solvent was efficacious with the LC50\% (the concentrate that kills $50 \%$ of the animals tested on) concentration of garlic extracts similar to that for various organochlorine and organophosphorus (Dieldrin; Malathion; Fenthion; Dichlorodiphenyltrichloroethane). However, external validity (e.g. oral or topical application of garlic to the dog with, or at risk of, flea parasitism) should not be inferred from these findings due to the numerous differences between laboratory and clinical application.

There is some evidence of in vitro efficacy of garlic application across parasitised species and ectoparasites from various phyla, which suggests that it may have its place as a plant-based ectoparasiticide for the ethnoveterinary based treatment of some species. In two cattle-based studies (both abstract only as the full text was in Spanish), oral supplementation with garlic (100 g or $200 \mathrm{~g}$ per cow; Massariol et al., 2009) or garlic residue (3-9 g per cow; de Castro Alvarenga et al., 2004) resulted in a significant reduction in ticks, similar to those cattle treated with Amitraz 0.025\% (Massariol et al., 2009). However, no significant effect was seen on horn, stable or house fly burden (Massariol et al., 2009). Similarly, topical (vent/abdomen; Birrenkott et al., 2000) or environmental (hen housing; Gorji et al., 2014) application saw a significant decrease in northern fowl mite by week 4 compared to baseline and the control group (Birrenkott et al., 2000) and an 85\% reduction in red mite infestation after the first application (Gorji et al., 2014). Topical (Gholipour-Kanai et al., 2012; and Fridman et al., 2014) or oral (Fridman et al., 2014) application of garlic extracts have also been shown to effectively reduce or eliminate ectoparasitism by the protozoan Ichthyophthirius multifiliis (host was a Sail Fin Molly fish; Gholipour-Kanai et al., 2012) and various trematode Mongean species (host was a Guppy fish; Fridman et al, 2014). This cross phyla efficacy may suggest a tentative basis for clinical research to investigate the efficacy of garlic as a plant-based ectoparasiticide to prevent, repel or kill fleas in the domestic dog. However, until garlic has been shown to be efficacious against fleas in dogs (and at levels non-toxic to the canine) the veterinary professional cannot make assumptions of external validity based on the studies cited, and clients should be recommended to use instead an ectoparasiticide that has been demonstrated to be so. 


\section{Methodology Section}

\begin{tabular}{|c|c|}
\hline \multicolumn{2}{|l|}{ Search Strategy } \\
\hline $\begin{array}{r}\text { Databases searched and dates } \\
\text { covered: }\end{array}$ & $\begin{array}{l}\text { Pubmed on NCBI platform (01/01/1900 - 03/12/2019); Web of Science } \\
\text { (1900 - 03/12/2019); CAB Abstracts on Ovid Platform }(1973-2019 \text {, } \\
\text { week 47); SCOPUS (1960 - 03/12/2019) }\end{array}$ \\
\hline Search terms: & $\begin{array}{l}\text { PubMed: } \\
\text { (dog OR dogs OR canine OR canid OR canis OR bitch OR bitches OR pup } \\
\text { OR puppy OR puppies) AND (garlic OR “allium sativum") AND (flea or } \\
\text { fleas or Ctenocephalides or ectoparasiticide or ectoparasite) } \\
\text { Web of Science: } \\
\text { (dog OR dogs OR canine OR canid OR canis OR bitch OR bitches OR pup } \\
\text { OR puppy OR puppies) AND (garlic OR “allium sativum") AND (flea or } \\
\text { fleas or Ctenocephalides or ectoparasiticide or ectoparasite) } \\
\text { CAB Abstracts: } \\
\text { (dog OR dogs OR canine OR canid OR canis OR bitch OR bitches OR pup } \\
\text { OR puppy OR puppies) AND (garlic OR allium sativum) AND (flea or fleas } \\
\text { or Ctenocephalides or ectoparasiticide or ectoparasite) } \\
\text { SCOPUS: } \\
\text { (dog OR dogs OR canine OR canid OR canis OR bitch OR bitches OR pup } \\
\text { OR puppy OR puppies) AND (garlic OR “allium sativum") AND (flea or } \\
\text { fleas or Ctenocephalides or ectoparasiticide or ectoparasite) }\end{array}$ \\
\hline Dates searches performed: & 03 Dec 2019 \\
\hline
\end{tabular}

Exclusion / Inclusion Criteria

Exclusion: Pre-defined exclusion criteria: non-English language, popular press articles, in vitro studies, conference abstracts

Inclusion: Any comparative study in which the effect of orally or topically administered garlic on flea parasitism of the dog was studied 


\begin{tabular}{|c|c|c|c|c|c|c|}
\hline \multicolumn{7}{|c|}{ Search Outcome } \\
\hline Database & $\begin{array}{c}\text { Number } \\
\text { of } \\
\text { results }\end{array}$ & $\begin{array}{l}\text { Excluded - } \\
\text { did not } \\
\text { address } \\
\text { the PICO }\end{array}$ & $\begin{array}{c}\text { Excluded - not } \\
\text { English } \\
\text { language }\end{array}$ & $\begin{array}{l}\text { Excluded - } \\
\text { conference } \\
\text { abstract only }\end{array}$ & $\begin{array}{l}\text { Excluded - } \\
\text { duplicates }\end{array}$ & $\begin{array}{c}\text { Total } \\
\text { relevant } \\
\text { papers }\end{array}$ \\
\hline PubMed & 1 & 1 & 0 & 0 & 0 & 0 \\
\hline $\begin{array}{l}\text { Web of } \\
\text { Science }\end{array}$ & 1 & 1 & 0 & 0 & 0 & 0 \\
\hline $\begin{array}{l}\text { CAB } \\
\text { Abstracts }\end{array}$ & 1 & 1 & 0 & 0 & 0 & 0 \\
\hline Scopus & 2 & 2 & 0 & 0 & 0 & 0 \\
\hline \multicolumn{6}{|c|}{ Total relevant papers } & 0 \\
\hline
\end{tabular}

\section{CONFLICT OF INTEREST}

The author declares no conflicts of interest.

\section{REFERENCES}

1. Birrenkott, G. P., Brockenfelt, G. E., Greer, J. A. \& Owens, M. D. (2000). Topical application of garlic reduces northern fowl mite infestation in laying hens. Poultry Science 79(11): 1575-1577.

DOI: http://dx.doi.org/10.1093/ps/79.11.1575

2. De Castra Alvarenga, L., de Aguiar Paiva, P. C., Banys, V. L., Collao-Saenz, E. A., Rabelo, A. M. G. \& de Rezende, A. P. (2004). Alternation of the thicks load of bovines under intake of different levels of residuals of the improvement of garlic. Ciencia E Agrotecnologia 28(4): 906-912.

DOI: http://dx.doi.org/10.1590/S1413-70542004000400025

3. Gholipour-Kanani, H., Sahandi, J. \& Taheri, A. (2012). Influence of garlic (Allium sativum) and Mother worth (Matricaria chamomilla) extract on Ichthyophtirius multifilus parasite treatment in Sail Fin Molly (Poecilia latipinna) ornamental fish. Procedia APCBEE 4: 6-11.

DOI: http://dx.doi.org/10.1016/j.apcbee.2012.11.002

4. Gorji, S. F., Gorji, S. F. \& Rajablon, M. (2014). The field efficacy of garlic extract against Dermanyssus gallinae in layer farms of Babol, Iran. Parasitology Research 113: 1209-1213.

DOI: http://dx.doi.org/10.1007/s00436-014-3759-2

5. Fridman, S., Sinai, T. \& Zilberg, D. (2014). Efficacy of garlic based treatments against monogean parasites infecting the guppy (Poecilia reticulata (Peters)). Veterinary Parasitology 203: 51-58. DOI: https://doi.org/10.1016/j.vetpar.2014.02.002 
6. Massariol, P. B., Olivio, C. J., Richards, N., Agnolin, C. A., Meinerz, G. R., Both, J. F., Faccio, L., Hohenreuther, F. \& Martinelli, S. (2009). Ectoparasite load alteration in Holstein cows fed with different garlic (Allium sativum L.) levels. Revista Brasileira de Plantas Medicinais 11(1): 37-42. DOI: http://dx.doi.org/10.1590/S1516-05722009000100007

7. Renapurkar, D. M. \& Deshmukh, P. B. (1984). Pulicidal activity of some indigenous plants. Insect Science and its Application 5(2): 101-102. DOI: http://dx.doi.org/10.1017/S1742758400001740 


\section{EVIIDEFeE

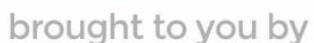 \\ RCVS KNOWLEDGE}

\section{Intellectual Property Rights}

Authors of Knowledge Summaries submitted to RCVS Knowledge for publication will retain copyright in their work, and will be required to grant RCVS Knowledge a non-exclusive license of the rights of copyright in the materials including but not limited to the right to publish, re-

publish, transmit, sell, distribute and otherwise use the materials in all languages and all media throughout the world, and to license or permit others to do so.

\section{Disclaimer}

Knowledge Summaries are a peer-reviewed article type which aims to answer a clinical question based on the best available current evidence. It does not override the responsibility

of the practitioner. Informed decisions should be made by considering such factors as individual clinical expertise and judgement along with patient's circumstances and owners' values. Knowledge Summaries are a resource to help inform and any opinions expressed within the Knowledge Summaries are the author's own and do not necessarily reflect the view of the RCVS Knowledge. Authors are responsible for the accuracy of the content. While the

Editor and Publisher believe that all content herein are in accord with current recommendations and practice at the time of publication, they accept no legal responsibility

for any errors or omissions, and make no warranty, express or implied, with respect to material contained within.

For further information please refer to our Terms of Use.

RCVS Knowledge is the independent charity associated with the Royal College of Veterinary Surgeons (RCVS). Our ambition is to become a global intermediary for evidence based veterinary knowledge by providing access to information

that is of immediate value to practicing veterinary professionals and directly contributes to evidence based clinical decision-making.

https://www.veterinaryevidence.org/

RCVS Knowledge is a registered Charity No. 230886.

Registered as a Company limited by guarantee in England and Wales No. 598443.

Registered Office: Belgravia House, 62-64 Horseferry Road, London SW1P 2AF

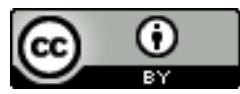

This work is licensed under a Creative Commons Attribution 4.0 International License 